\title{
WHO Guided Real Time Stability Testing on Shankhpushpi Syrup
}

\section{ASTHA JAIN, JASMEEN KAUR, NANCY, YOGITA BANSAL, BALRAJ SAINI AND GULSHAN BANSAL*}

Department of Pharmaceutical Sciences and Drug Research, Punjabi University, Patiala - 147001, Punjab, India.

*Email: gulshanbansal@rediffmail.com

Received: Dec. 02, 2016 I Revised: Feb. 03, 2017 I Accepted: March 03, 2017

Published online: May 05, 2017

The Author(s) 2017. This article is published with open access at www .chitkara.edu. in/publications

\begin{abstract}
Shankhpushpiis widely used herb in numerous CNS active Ayurvedic formulations, which are consumed by population of all age groups. The present study is designed to evaluate the stability of commercially available shankhpushpi syrup as per WHO guidelines. The study was conducted under long term conditions for 12 months on three different batches of the product. An HPLC-UV method was developed and validated to determine the marker (scopoletin) content in the stability samples. Peak purity was determined using HPLC-PDA analysis. Each stability sample was investigated for any change in physical, chemical and biological parameters with respect to control sample. The product was found to be stable in terms of physical parameters whereas significant change was observed in total phenolic content and content of scopoletin. The antioxidant, acetylcholine esterase inhibitory and antianxiety activities of the stability samples decreased with respect to control sample. Moreover, there was significant variation in chemical and biological parameters among the batches. The findings suggested that the product was unstable and further studies are required to be conducted in order to determine the shelf life of the product.
\end{abstract}

Keywords: Stability study, Convolvulus pluricaulis, Bacopamonnieri, Shankhpushpi syrup, Scopoletin, HPLC-UV, HPLC-PDA

\section{INTRODUCTION}

CNS active herbs and herbal products contribute a significant share to herbal drug market across the globe (Kumari, S. et al, 2011).These are consumed
Journal of Pharmaceutical Technology, Research and Management Volume 5, No. 1, May 2017 pp. 1-19 
Jain, A

Kaur, $\mathrm{J}$

Nancy,

Bansal, Y

Saini, B

Bansal, G

by population of all age groups without any prescription, especially in the developing countries, indiscriminately for varied purposes such as to relieve anxiety, depression and memory loss. Convolvulus pluricaulis and Bacopamonnieri are the most common herbs used in different CNS active herbal products available in market. Various drugs regulatory agencies such as World Health Organization (WHO), International Conference on Harmonization (ICH) and European Medicine Agency (EMEA) have issued specific guidelines for establishing shelf life of any medicinal product through systematic stability studies(CPMP, 2003; EMEA, 2008; EMEA 2010; ICH, 2003; WHO, 2009). These guidelines also mention that shelf life recommendation should be basedon chemical stability, chromatographic fingerprinting and biological activity evaluation. Though some reports on chemical stability of $C$. pluricaulis and B. monnieri are available in literature (Phrompittayarat, W. et al, 2008; Shahare, M.D. et al, 2010; Srivastava, P. et al, 2010; Srivastava, P. et al, 2012), but the conditions and duration employed for their stability studies in these reports are not in accordance with the recommendations of the regulatory guidelines.

The present study reveals stability testing on three batches of a commercially available herbal product composed of $C$. pluricaulis and $B$. monnieri under long term storage condition $\left(30^{\circ} \mathrm{C} / 75 \% \mathrm{RH}\right)$ as specified in WHO and ICHguidelines.The objective is to study any chemical and/or therapeutic change(s) in the formulation during storage through evaluation of physical, chemical and biological parameters. Each control and stability sample was evaluated for physicochemical stability in terms of appearance, $\mathrm{pH}$, viscosity, total phenolic content (TPC), content of markers (scopoletin and bacoside A), and for different biological activities including antioxidant, acetylcholinesterase(AChE) inhibitory and anxiolytic activities.

\section{MATERIALS AND METHODS}

\subsection{Materials}

Three batches (A, B and C) of Shankhpusphi syrup were purchased from local pharmacy store. All three batches were stored under long term stability conditions $\left(30 \pm 2{ }^{\circ} \mathrm{C} / 65 \pm 5 \% \mathrm{RH}\right)$ and samples were withdrawn at $3,6,9$ and 12 months. The control samples (0 time) as well as each stability sample were stored at $4^{\circ} \mathrm{C}$ till physicochemical and biological evaluations performed. Scopoletin, $\alpha, \alpha$-Diphenyl- $\beta$-picrylhydrazyl (DPPH), acetylthiocholine iodide (ATCI), acetylcholinesterase (AChE, electric eel, type VI-S lyophilized powder,480U/mg solid, 530U/mg protein), Bovine Serum Albumin (BSA) and 5,5-dithiobis (2-nitrobenzoic acid) (DTNB) were purchased from Sigma- 
Aldrich (Bengaluru, India). Bacoside A was purchased from Natural remedies (Bengaluru, India). Folin-Ciocalteu phenol reagent, methanol (HPLC grade), acetonitrile (HPLC grade) were obtained from Merck Specialist Pvt. Ltd. (Mumbai, India). Gallic acid was purchased from $\mathrm{Hi}-$ media Laboratories Pvt. Ltd.(Mumbai, India). Calmpose injection (label claim; Diazepam HCl, 10mg) manufactured by Ranbaxy Laboratories (Gurgaon, India) was purchased from local pharmacy. All other chemicals and solvents were procured from S.D. fine chemicals(Mumbai, India).

\subsection{Instruments}

The HPLC system consisted of binary pumps (515), dual wavelength detector (2487) and Rheodynemanual injector (Waters, Milford, MA, USA). The data was acquired and processed in Empower 2 software (Waters, MA, USA). The chromatographic separation of the samples were achieved on Nucleodur C18 $(250 \times 4.6 \mathrm{~mm} ; 5 \mu)$ and on XTerra C18 $(250 \times 4.6 \mathrm{~mm} ; 5 \mu)$ column. The mobile phase was filtered through nylon membrane $(0.45 \mu \mathrm{m})$ using Millipore filter assembly and was degassed using transonic sonicator bath (570/H ELMA, Germany). The LC-PDA analysis was carried out on Waters HPLC system consisting of pumps (515), auto injector (2707), and PDA detector (2998) (Milford, MA, USA). Samples were lyophilized using lyophilizer (Allied Frost, Macflow Engineering, Pvt. Ltd., New Delhi, India). UV spectrophotometer (DU ${ }^{\circledR} 640$ B series, Beckman, USA) was used for spectrophotometric analysis. The $\mathrm{pH}$ was measured using digital $\mathrm{pH}$ meter (Five Easy plus FEP 20-ATC kit, Mettler Toledo AG, Analytical, Schwerzenbach, Switzerland). Brookfield viscometer (LVDV - 1 Prime viscometer, Brookfield Engineering Laboratories, New York, USA) was used for testing viscosity of each stability sample. Hot air oven equipped with digital temperature control capable of controlling temperature within range of $\pm 2^{\circ} \mathrm{C}$ (Gupta Scientific Works, Ambala, India) was used for drying purposes. Stability studies were performed by using a stability chamber (Rolex Scientific Engineers, Ambala, India) capable of controlling temperature and humidity within range of $\pm 2^{\circ} \mathrm{C}$ and $\pm 5 \% \mathrm{RH}$, respectively. The chamber was set at temperature of $30^{\circ} \mathrm{C}$ and $65 \% \mathrm{RH}$.

\subsection{Methods}

\subsubsection{Stability Studies}

All three batches of the formulation were stored under long term stability conditions $\left(30 \pm 2{ }^{\circ} \mathrm{C} / 65 \pm 5 \% \mathrm{RH}\right)$ and samples were withdrawn at 3, 6, 9 and 12 months. The control samples (0 time) as well as each stability sample were stored at $4{ }^{\circ} \mathrm{C}$ till physicochemical and biological studies performed. 
Jain, A

Kaur, $\mathrm{J}$

Nancy,

Bansal, Y

Saini, B

Bansal, G

\subsubsection{Physical Evaluation}

Each of the control and stability sample was evaluated for its organoleptic properties such as color, clarity, odor, taste, $\mathrm{pH}$ and viscosity. Viscosity was measured at $25 \pm 2^{\circ} \mathrm{C}$ using small volume adaptor at $20 \mathrm{rpm}$ using Brookfield viscometerby the method as reported by Arslan, E. et al (2005). The $\mathrm{pH}$ and viscosity of each sample was recorded in triplicate.

\subsubsection{Chemical Evaluation}

\section{Total Phenolic Content}

TPC was determined as grams ofgallic acid equivalent (gGAE)/L by the FolinCiocalteu's method reported by Fu, L. et al (2011) with some modifications.A stock solution $(100 \mu \mathrm{g} / \mathrm{mL})$ of gallic acid in water was diluted to obtain a series of standard solutions of concentrations $10,20,30,40,50,60,70,80,90$ and $100 \mu \mathrm{g} / \mathrm{mL}$. A $0.5 \mathrm{~mL}$ aliquot of each solution was mixed with $2.5 \mathrm{~mL}$ of $1: 10$ diluted Folin-Ciocalteu's reagent and allowed to incubate at room temperature for $5 \mathrm{~min}$. Subsequently, $2 \mathrm{~mL}$ of saturated sodium carbonate solution $(75 \mathrm{~g} / \mathrm{L})$ was added, mixed well and left to stand for $30 \mathrm{~min}$ at room temperature. The absorbance of the resulting solution was read at $760 \mathrm{~nm}$ taking water as blank. A calibration curve was constructed taking concentration of gallic acid as abscissa and absorbance as ordinate. The curve was constructed in triplicate using fresh sets of standard solutions. Each of the control and stability sample (diluted 1 in 32 with water) was processed similar to the standard solution of gallic acid to determine percent change in $(\mathrm{gGAE}) / \mathrm{L}$ of each stability sample w.r.t. its control.

\section{Scopoletin and Bacoside A Contents}

A $5 \mathrm{~mL}$ aliquot of each control and stability samplewas lyophilized.The resultant dried solid was dissolved in $10 \mathrm{~mL}$ of methanol. $1 \mathrm{~mL}$ of this solution was diluted with equal volume of methanol to obtain sample solution.Separate solutions of the most common excipients used for syrups i.e., sodium benzoate, citric acid, propyl paraben and methyl paraben were also prepared $(0.1 \mathrm{mg} / \mathrm{mL})$ in methanol. The standard solutions of scopoletin and bacoside A, solutions of each control and stability sample, and solutions of excipients were analyzed through HPLC to determine the contents ofscopoletin and bacoside $\mathrm{A}$ in each sample. The samples were optimally chromatographed for determination of scopoletin on Nucleodur C18 $(250 \times 4.6 \mathrm{~mm} ; 5 \mu)$ column by isocratic elution with mobile phase composed of acetonitrile and phosphate buffer $(20 \mathrm{mM}, \mathrm{pH} 3.5)(20: 80 \% \mathrm{v} / \mathrm{v})$ and for determination ofbacoside A on XTerra C18 $(250 \times 4.6 \mathrm{~mm} ; 5 \mu)$ column by mobile phase composed of acetonitrile and $0.2 \% \mathrm{o}-$ phosphoric 
acid $(35: 65 \% \mathrm{v} / \mathrm{v})$ flowing at a rate of $1 \mathrm{~mL} / \mathrm{min}$ at ambient temperature. The injection volume was fixed at $20 \mu \mathrm{L}$ and the eluent was detected at $205 \mathrm{~nm}$. The LC-PDA analysis of standard scopoletin solution and control samples of all three batches of formulation was carried out to establish purity of the scopoletin peak.

\subsubsection{Pharmacological Activity Evaluation}

\section{Antioxidant Activity}

It was evaluated as free radical scavenging activity using DPPH method as reported by Locatelli, M. et al (2009) with some modifications. A solution of DPPH $(100 \mu \mathrm{M}, 1 \mathrm{mg} / 25 \mathrm{~mL})$ was prepared in methanol and kept in dark at $4^{\circ} \mathrm{C}$. The stability sample $(1 \mathrm{~mL})$ was mixed well with same volume of DPPH solution $(100 \mu \mathrm{M})$ and left to stand in dark at room temperature for $180 \mathrm{~min}$. Absorbance (A) of the solution was read at 515nm against methanol as blank. Each sample was assayed in triplicate. Anti-radical activity was expressed as inhibition percentage (I\%) and calculated against negative control (where sample solution was replaced with same volume of methanol) using the following equation:

$$
\mathrm{I} \%=\left[\left(\mathrm{A}_{\text {negative control }}-\mathrm{A}_{\text {sample }}\right) / \mathrm{A}_{\text {negative control }}\right] \times 100
$$

I\% for control sample of each batch of the syrup was determined at different dilutions i.e., 1/8, 1/16, 1/32, 1/64 and 1/128 in methanol corresponding to concentrations of $12.5,6.25,3.13,1.56$ and $0.781 \% \mathrm{v} / \mathrm{v}$, respectively. $\mathrm{IC}_{50}$ was calculated through probit regression as reported by Locatelli, M. et al (2009) and expressed as percent concentration of the syrup $(\% \mathrm{v} / \mathrm{v})$. Subsequently, the anti-radical activity (I\%) of control and stability samples was evaluated at $1 \% \mathrm{v} / \mathrm{v}$ for batch $\mathrm{B}$ and $2 \% \mathrm{v} / \mathrm{v}$ for batches $\mathrm{A}$ and $\mathrm{C}$.

\section{AChE Inhibitory Activity}

It was measured by the spectrophotometric method developed by Ellman, G.L.et al (1961)with some modifications.A mixture of $1500 \mu \mathrm{L}$ of phosphate buffer (0.1 M, pH 8.0), 200 $\mu \mathrm{L}$ of DTNB $(4 \mathrm{mM}), 100 \mu \mathrm{L}$ of stability sample solution and $100 \mu \mathrm{L}$ of $\mathrm{AChE}$ solution $(0.1 \mathrm{U} / \mathrm{mL})$ was incubated for $10 \mathrm{~min}$ at $25^{\circ} \mathrm{C}$. The reaction was initiated by the addition of $100 \mu \mathrm{L}$ ATCI solution $(14 \mathrm{mM})$ and monitored at $405 \mathrm{~nm}$. For negative control, the stability sample was replaced with water. All samples were analyzed in triplicate. The percent inhibition (I\%) of AChE was calculated by formula $\mathrm{I} \%=\left(\mathrm{A}_{\mathrm{N}}-\mathrm{A}_{\mathrm{S}}\right) / \mathrm{A}_{\mathrm{N}} \times$ 100 , where, $A_{N}$ is absorbance of negative control and $A_{S}$ is absorbance of stability sample.
WHO Guided

Real Time

Stability Testing on Shankhpushpi

Syrup 
Jain, A

Kaur, $\mathrm{J}$

Nancy,

Bansal, Y

Saini, B

Bansal, G

Antianxiety Activity

Swiss albino mice (20-25 g) of either sex were procured from Disease Free Small Animal House (ChaudharyCharan Singh Haryana Agricultural University, Hisar, Haryana).These were kept in animal house of Punjabi University, Patiala and fed with standard rodent diet and tap water ad libitum. Animals were exposed to natural photoperiod and were acclimatized to the laboratory conditions before experiments. The experimental protocol was duly approved by Institutional Animal Ethics Committee (IAEC) and care of the animals was taken as per guidelines of the Committee for the Purpose of Control and Supervision of Experiments on Animals (CPCSEA), Ministry of Environmental and Forest, Government of India, (Reg.No. 107/99/ CPCSEA-2012-24). Diazepam hydrochloride was used as a standard anxiolytic drug and was administered in dose of $2 \mathrm{mg} / \mathrm{kg}$ i.p. Normal saline was used as a control.

Elevated plus maze (EPM) test: The plus maze apparatus consisting of two open arms measuring $16 \times 5 \mathrm{~cm}$, and two closed arms measuring $16 \times 5 \times 12 \mathrm{~cm}$, connected to a central platform $(5 \times 5 \mathrm{~cm})$ was elevated to a height of $25 \mathrm{~cm}$ above the floor. Each mouse was placed individually in the centre of EPM with its head facing toward an open arm and was observed for $5 \mathrm{~min}$. The behavior of the mouse was recorded as: (i) preference of the mouse for its first entry into the open or closed arms, (ii) number of entries into the open or closed arms, and (iii) time spent by the mouse in each of the arms (Kulkarni, S.K. et $a l, 1999)$.Every precaution was taken to ensure that no external stimuli, other than height of plus maze could invoke anxiety.

Light-dark exploration test: The test apparatus consisted of a small dark secure compartment (one-third) and a large illuminated aversive compartment (two-thirds). The two compartments were connected by a small opening in the wall between the two compartments. An animal was placed in the centre of the light compartment and was observed for $5 \mathrm{~min}$. The apparatus was cleaned thoroughly between trials with damp and dry towels. The mice were observedfor the number of crossings between two compartments and time spent in the light and dark compartments. This test has the advantages of being quick and easy to use, without requiring the prior training of animals (Bourin, M. et al, 2003).

Open field exploration test: It provides simultaneous measures of locomotion, exploration and anxiety. The open field apparatus measured $72 \times 72 \mathrm{~cm}$ with $36 \mathrm{~cm}$ walls. Floor of the field was divided into sixteen $(18 \times 18 \mathrm{~cm})$ squares. A central square was also drawn in the middle of the open field (Brown, R.E. et al, 1999). Mouse was placed in the centre of the central square and 
spontaneous ambulatory locomotion of each mouse was quantified for $5 \mathrm{~min}$. During this period, the number of squares crossed, centre squares entries, time spent in centre squares and number of rearing were measured.

\subsubsection{Statistical Analysis:}

The data were expressed as mean \pm standard error mean (SEM). The significance of differences among the groups was assessed using one way analysis of variance (ANOVA). The test was followed by Dunnett's ' $t$ ' - test, $p$ values less than 0.05 were considered as significant.

\section{RESULTS AND DISCUSSION}

\subsection{PhysicalEvaluation}

Control sample of each batch was clear, dark green in color, pleasant to smell and sweet to taste. All stability samples retained these organoleptic characters indicating no visible and perceptible change during storage for one year. Viscosity of control samples of the batch A, B and C was found to be $24.80 \pm 0.02,22.10 \pm 0.02$ and $19.70 \pm 0.02 \mathrm{cps}$, respectively, and only small negligible change was found in stability samples with time (Figure 1). ThepH of control sample of each batch was in the range of 4.04 to 4.20, and it changed insignificantly $( \pm 0.10$ units $)$ upon storage. These results indicated that there

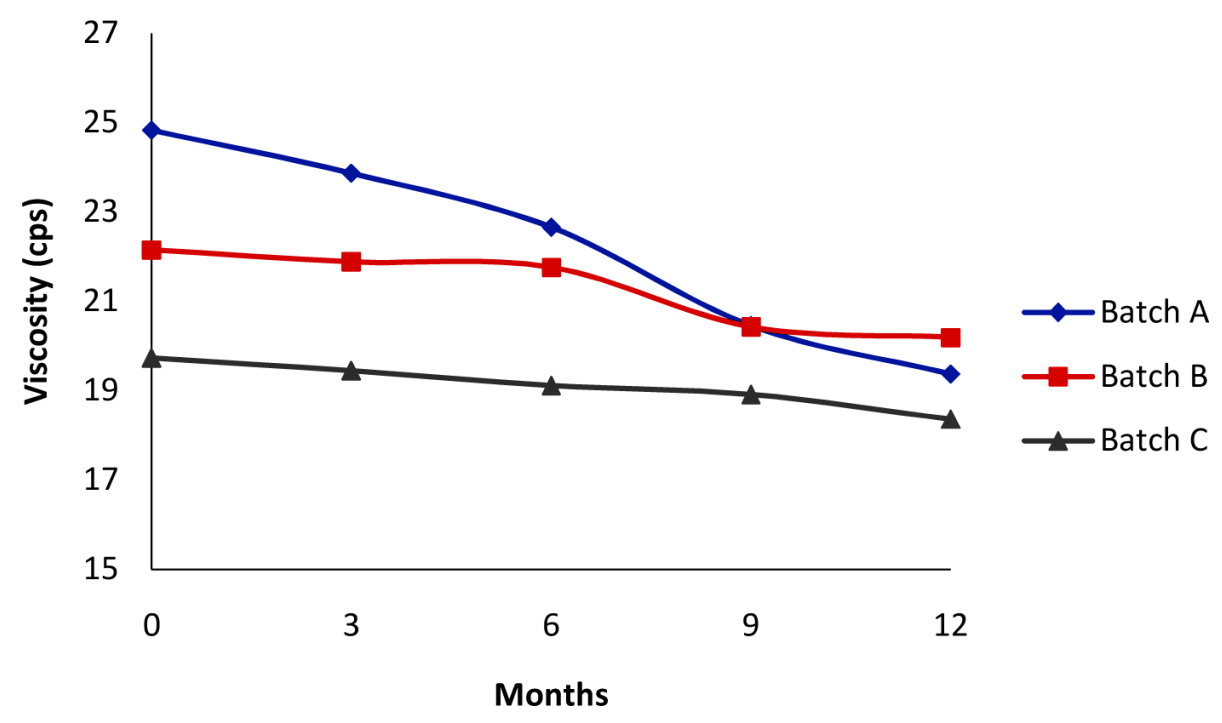

Figure 1: Viscosity of batches A, B and C at different times during stability testing. 
Jain, A

Kaur, J

Nancy,

Bansal, Y

Saini, B

Bansal, G was no significant change in physical stability of any batch of the product after storage for one year under long term stability conditions.

\subsection{Chemical Evaluation}

Chemical stability of the products was assessed in terms of total phenolic content (TPC) and content of marker compounds (Scopoletin for C. pluricaulis and Bacoside A for B. monnieri).

\subsubsection{Total Phenolic Content}

TPC was determined as gram of gallic acid equivalent per litre (gGAE/L) using Folin-Ciocalteu's method as reported by Fu, L. et al (2011).This method was optimized for the present study, and found linear for gallic acid in the concentration range of $0.01-0.10 \mu \mathrm{g} / \mathrm{mL}(\mathrm{y}=10.236 \mathrm{x}+0.0512)$ with a correlation coefficient of 0.9992 . A 1/32 diluted sample of each batch showed TPC within the established linearity range.Hence, control and stability samples of each batch were diluted 32 times to obtain working solutions for TPC determination. TPC of stability sampleof each of the three batches was found to decrease as reflected by $\%$ change in gGAE/Lwith time with respect to its corresponding control (Figure 2). While batches

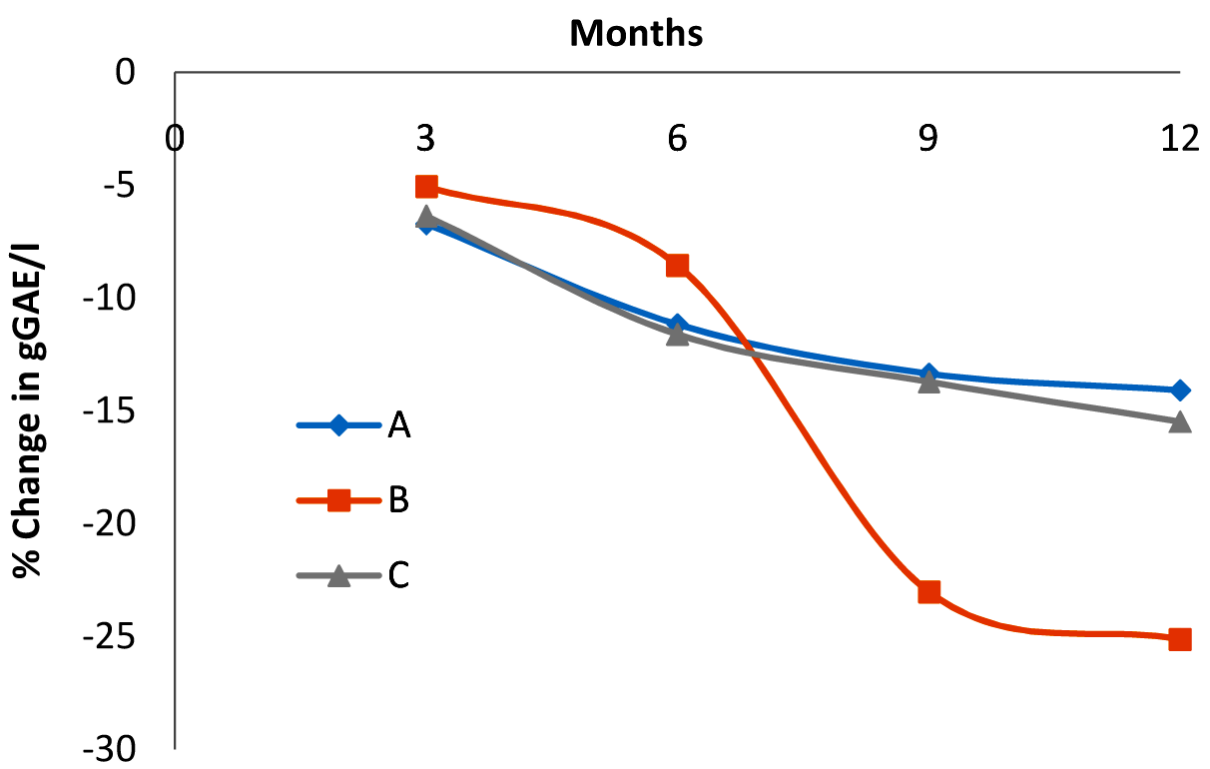

Figure 2: Percent change in gGAE/L of batch $\mathrm{A}$, batch $\mathrm{B}$ and batch $\mathrm{C}$ with respect to the respective control after $3,6,9$ and 12 months. 
A and $\mathrm{C}$ showed 14-16\% decrease, batch B showed maximum decrease of $25 \%$ after 12 months of storage. These findings indicate that phenolic compounds are unstable in the product, and their level falls with ageing of the product.

\subsubsection{Scopoletin and Bacoside A Contents}

Contents of scopoletin and bacoside A were determined by separate HPLC methods. Bacoside A was eluted as a characteristic set of 5 peaks within 22-40 $\min ($ Figure 3A) whereas scopoletin was eluted at 13 min (Figure 4A).Bacoside A was not detected in control samples of all the three batches (Figure 3), whereas

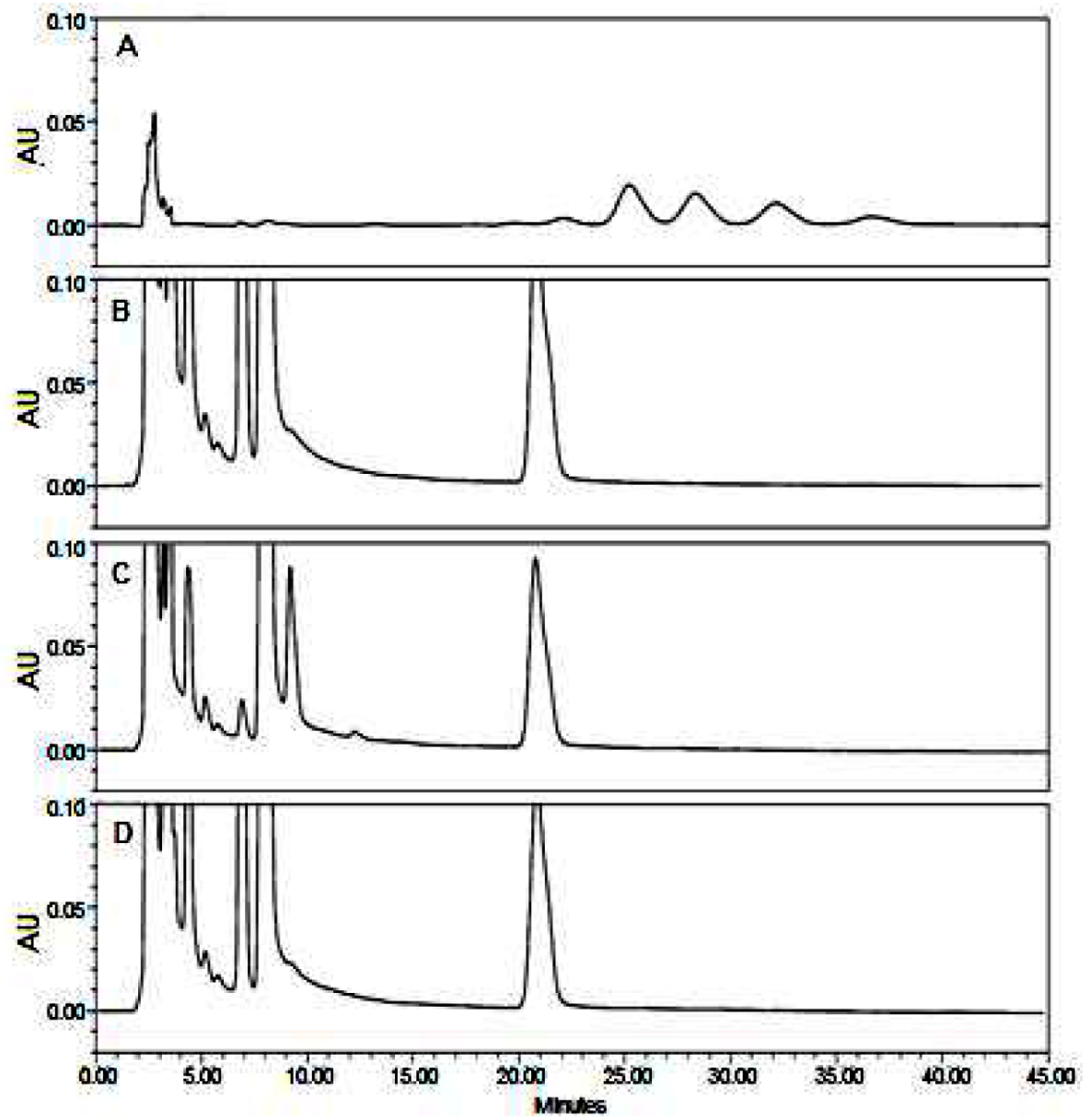

Figure 3: HPLC-UV chromatograms of bacosideA standard solution (A), and of control samples of batch A (B), batch B (C) and batch C (D).
WHO Guided

Real Time

Stability Testing on Shankhpushpi

Syrup 
Jain, A

Kaur, J

Nancy,

Bansal, Y

Saini, B

Bansal, G
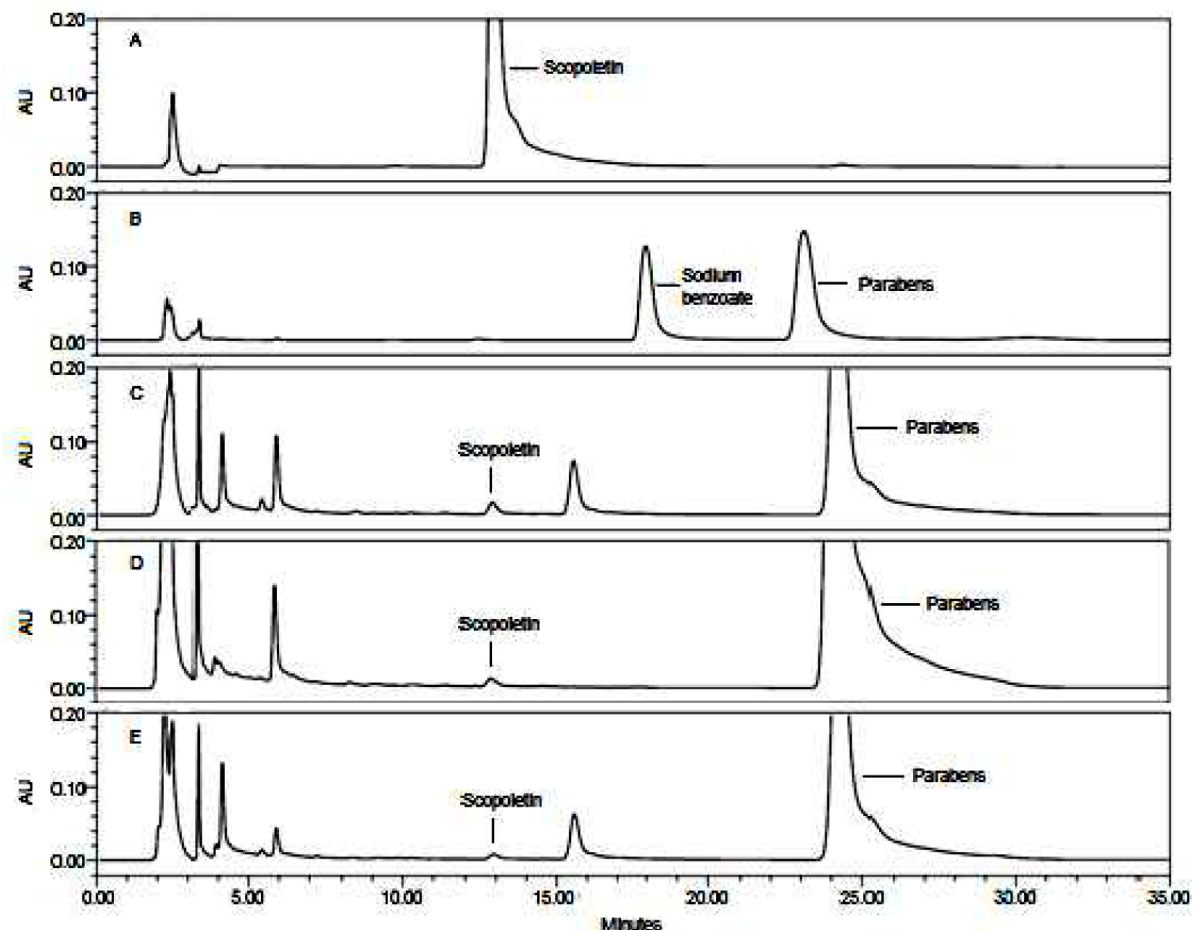

Figure 4: HPLC-UV chromatograms of scopoletin standard solution (A), excipients mixture(B), and of control samples of batch A (C), batch B (D) and batch $\mathrm{C}(\mathrm{E})$.

scopoletin was found in control sample of each batch (Figure 4). It revealed that though the label claim mentioned the product to contain B. monnieri but actually it was absent. Presence of scopoletin in each sample was confirmed through matching of retention times and UV absorption spectra of scopoletin obtained through LC-PDA analysis. UV absorption spectrum of scopoletin peak in standard solution was found matching with the spectrum of peak at 13 minin LC-UV chromatogram of each control sample (Figure 5). Out of the most commonly used excipients, only parabens were found in the formulations (Figure 4).The content of scopoletin in control samples of $\mathrm{A}$ and B was quite similar $(86.41$ and $95.36 \mu \mathrm{g} / \mathrm{mL})$ but it was very high in Batch $\mathrm{C}(158.01 \mu \mathrm{g} / \mathrm{mL})$ (Table 1).It was found to decrease with time in stability samples with respect to the control sample in each batch (Table 1). Further, change in scopoletin content in stability samples of all three batches showed a wide variability. It degraded by $56.52 \%, 59.21 \%$ and $31.42 \%$ in batches A, B and C, respectively, after 12 months storage. It suggested that initial content of scopoletinmay have some 
Table 1: Scopoletin content analysis of stability samples.

\begin{tabular}{llllll}
\hline $\begin{array}{l}\text { Product } \\
\text { Batch }\end{array}$ & \multicolumn{5}{l}{ Scopoletin content $(\boldsymbol{\mu g} / \mathbf{m L}$ of syrup) $\mathbf{a} \%$ Change with respect to control sample } \\
& Control & $\mathbf{3}$ month & $\mathbf{6}$ month & 9 month & 12 month \\
\hline A & $86.41 \pm 5.34$ & $67.46 \pm 3.37 ;$ & $52.85 \pm 0.59 ;$ & $46.34 \pm 1.84 ;$ & $37.57 \pm 3.93 ;$ \\
& & $-21.34 \pm 3.90$ & $-38.80 \pm 0.68$ & $-46.37 \pm 2.13$ & $-56.52 \pm 4.55$ \\
B & $95.36 \pm 4.23$ & $54.80 \pm 3.99 ;$ & $45.48 \pm 2.82 ;$ & $42.16 \pm 2.69 ;$ & $38.89 \pm 6.10 ;$ \\
& & $-42.53 \pm 4.19$ & $-52.30 \pm 2.96$ & $-55.68 \pm 2.82$ & $-59.21 \pm 6.40$ \\
C & \multirow{2}{*}{$158.01 \pm 2.13$} & $113.27 \pm 2.51 ;$ & $111.03 \pm 3.15 ;$ & $110.28 \pm 0.92 ;$ & $108.36 \pm 1.83 ;$ \\
& & $-28.31 \pm 1.59$ & $-29.73 \pm 1.99$ & $30.20 \pm 0.58$ & $31.42 \pm 1.15$ \\
\hline
\end{tabular}

${ }^{\mathrm{a}}$ values are expressed as mean $\pm \mathrm{SD}(\mathrm{n}=3)$

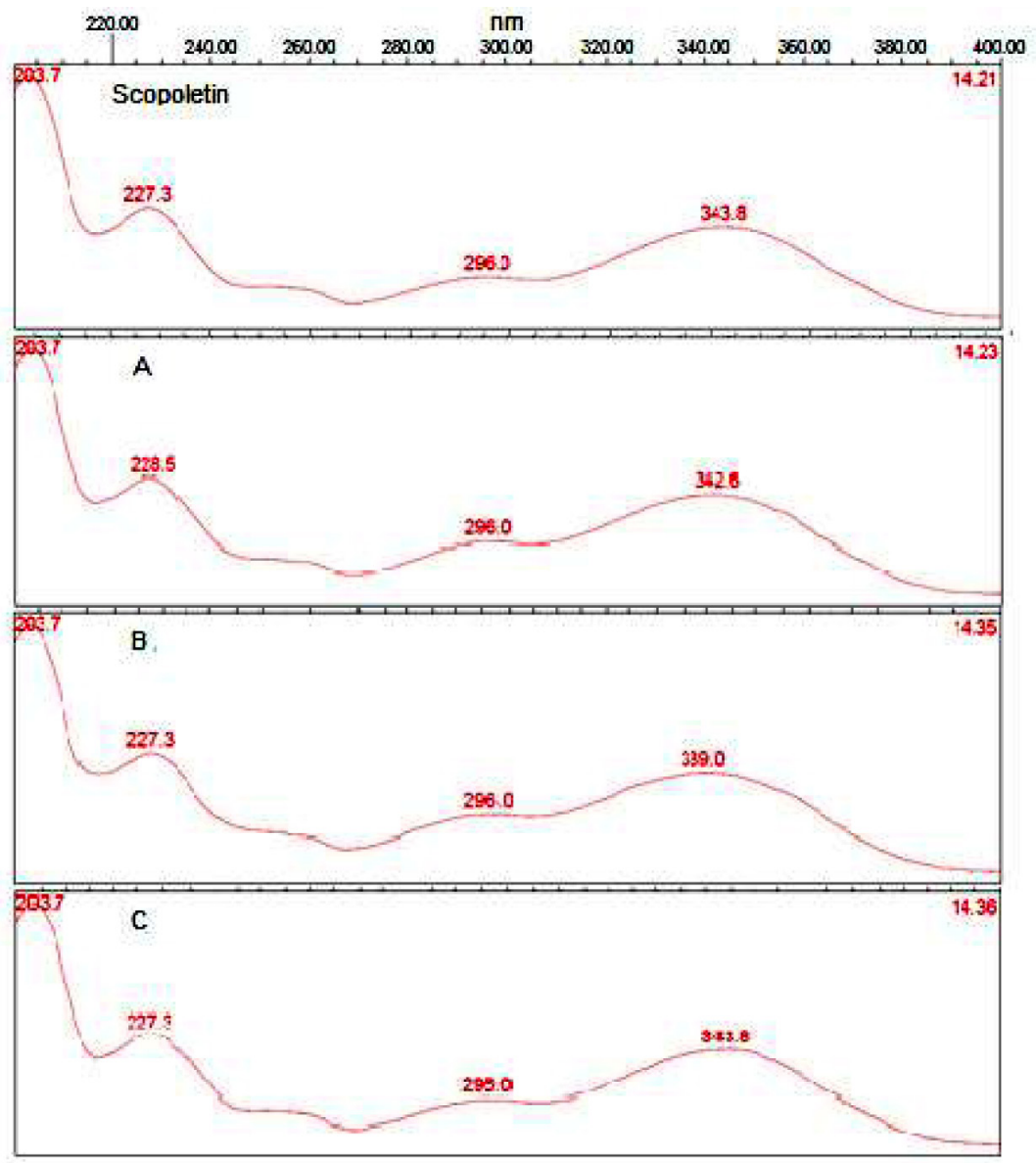

Figure 5: UV spectra of scopoletin peak in standard solution and control samples of batch A, batch B and batch C through LC-PDA studies.
WHO Guided Real Time Stability Testing on Shankhpushpi Syrup 
Jain, A

Kaur, $\mathrm{J}$

Nancy,

Bansal, $\mathrm{Y}$

Saini, B

Bansal, G

kinetic role in its degradation. Further, degradation during first three months was almost two times in batch B (42.53\%) than in batches A and C $(21.34 \%$ and $28.31 \%$, respectively). This variability may be attributed to different chemical architecture of the products. This proposition is based on the findings that LCUV chromatograms of control sample of batch $A$ and $C$ were similar but different from that of batch B. HPLC-UV chromatograms of representative batch A at five time points $(0,3,6,9$ and 12 months) along with standard scopoletin are shown in Figure 6.

\subsection{Pharmacological Activities}

In general, no single phytoconstituent or group of constituents is held solely responsible for a biological activity of any plant. Therefore, assessment of chemical stability of herbal productin terms of a particular marker or group of markers may not be translated into assessment oftherapeutic efficacy of the product. Hence, biological activity evaluation becomes an indispensible part of stability evaluation program of any herbal product. As the herbal products containing C. pluricaulis and B. monnieri are mainly used for treatment of CNS related disorders, the selected products in the present study were evaluated for their antioxidant, anticholinesterase and anxiolytic activities.

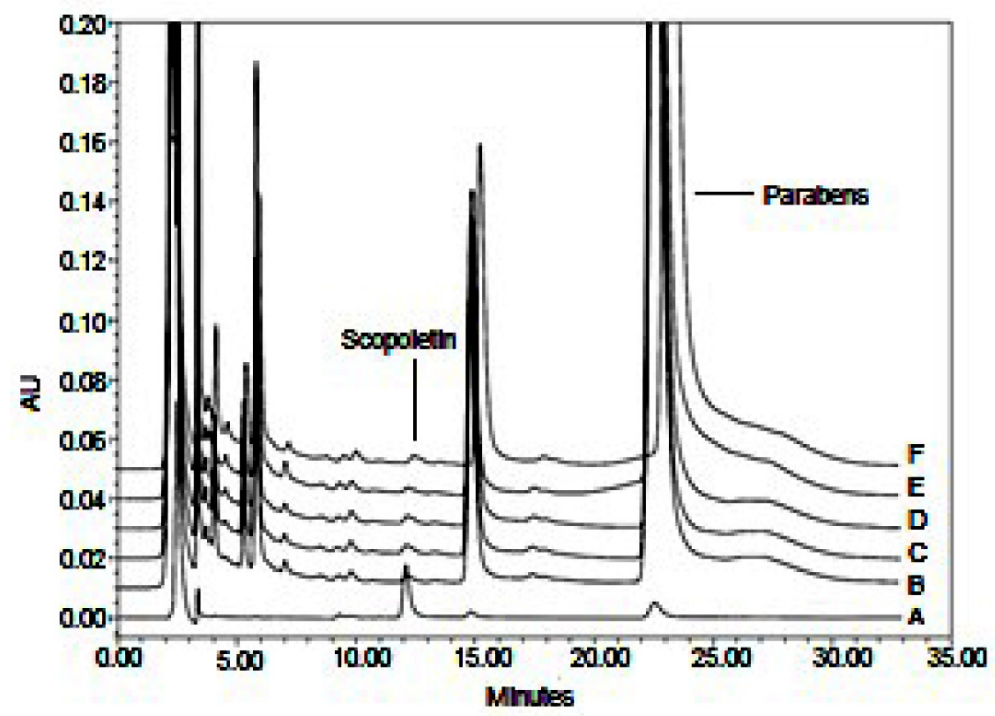

Figure 6: HPLC-UV chromatograms of scopoletin standard solution (A), and of stability samples of batch A at 0 time (B), 3 month (C), 6 month (D), 9 month (E) and 12 month (F). 


\subsubsection{Antioxidant Activity}

Antioxidant activity was determined as radical scavenging activity using DPPH model (Locatelli, M. et al, 2009). $\mathrm{IC}_{50}$ value of control samples of $\mathrm{A}, \mathrm{B}$ and $\mathrm{C}$ was found to be $2.39 \pm 0.14,0.94 \pm 0.05$ and $1.92 \pm 0.29 \% \mathrm{v} / \mathrm{v}$, respectively. It indicated that antioxidant activity of batches $\mathrm{A}$ and $\mathrm{C}$ was statistically similar but that of B was more than two times the other. Based on these $\mathrm{IC}_{50}$ values, antioxidant activity of batches $\mathrm{A}$ and $\mathrm{C}$ was evaluated at concentration of $2.0 \% \mathrm{v} / \mathrm{v}$, and that of batch $\mathrm{B}$ was evaluated at $1.0 \% \mathrm{v} / \mathrm{v}$ concentration. It was found that antioxidant activity decreased with time in all three batches (Table 2). In batch $\mathrm{A}$ and $\mathrm{C}$, the decrease was about $10 \%$ whereas in batch B, it was about $14 \%$. These changes were in consonant with the changes in TPC (Figure 2), which suggested that antioxidant activity of the products might be due to phenolic compounds in the product.

\subsubsection{AChE inhibitory activity}

AChE inhibitory activity of control sample of each of the three batches was statistically different that indicates significant batch to batch variation. The activity of each batch was found to decrease with time (Table 2). This decrease was greater for batch B $(-9.2 \%)$ than for batch $\mathrm{A}(-6.1 \%)$ and batch $\mathrm{C}$ $(-5.32 \%)$.

\subsubsection{Anxiolytic Activity}

Anxiolytic activity of each control and stability sample was evaluated using Elevated plus maze model (EPM) (Kulkarni, S.K., 1999), Light-Dark transition test (LDTT) (Bourin, M.et al, 2003)and Open field Test (OFT)

Table 2: Antioxidant and AChE inhibitory activities of different stability samples.

\begin{tabular}{|c|c|c|c|c|c|}
\hline Batch (conc.) & 0 month & 3 month & 6 month & 9 month & 12 month \\
\hline & \multicolumn{5}{|c|}{ Antioxidant activity (I\% of DPPH radical activity) ${ }^{\mathrm{a}}$} \\
\hline$A(2.0 \% \mathbf{v} / \mathbf{v})$ & $65.62 \pm 0.36$ & $59.53 \pm 0.65$ & $57.60 \pm 0.75$ & $55.53 \pm 0.47$ & $54.33 \pm 0.15$ \\
\hline B $(1.0 \% \mathrm{v} / \mathrm{v})$ & $64.30 \pm 0.85$ & $59.77 \pm 0.15$ & $58.95 \pm 0.64$ & $50.83 \pm 0.89$ & $50.07 \pm 0.74$ \\
\hline \multirow[t]{2}{*}{ C $(2.0 \% \mathrm{v} / \mathbf{v})$} & $64.90 \pm 0.95$ & $62.33 \pm 0.91$ & $59.01 \pm 0.92$ & $57.28 \pm 0.86$ & $55.71 \pm 0.69$ \\
\hline & \multicolumn{5}{|c|}{ AChE inhibitory activity (I\% of Acetylcholinesteraseactivity) ${ }^{\mathrm{a}}$} \\
\hline $\mathbf{A}$ & $38.09 \pm 0.60$ & $36.41 \pm 0.53$ & $34.81 \pm 0.66$ & $32.17 \pm 0.80$ & $31.98 \pm 0.62$ \\
\hline B & $31.66 \pm 0.15$ & $27.76 \pm 0.52$ & $25.67 \pm 0.16$ & $24.84 \pm 0.28$ & $22.46 \pm 0.16$ \\
\hline C & $29.40 \pm 0.13$ & $28.18 \pm 0.19$ & $26.72 \pm 0.47$ & $25.69 \pm 0.38$ & $24.08 \pm 0.27$ \\
\hline
\end{tabular}

${ }^{a}$ values are expressed as mean $\pm \mathrm{SD}(\mathrm{n}=3)$ 
Jain, A

Kaur, $\mathrm{J}$

Nancy,

Bansal, Y

Saini, B

Bansal, G

(Brown, R.E.et al, 1999) taking diazepam hydrochloride $(2 \mathrm{mg} / \mathrm{kg}$, i.p.) as standard drug. The dose of sample was calculated to be $5 \mathrm{~mL} / \mathrm{kg}$ by dose translation method as reported by Reagan-Shaw, S. et al(2008). Based on this calculated dose, each control and stability sample was administered orally at a dose of $0.1 \mathrm{~mL} / 10 \mathrm{~g}$ body weight of mice. In EPM, antianxiety activity is measured in terms of number of entries and time spent by animals in open and closed arms. A substance increasing the permanence of animals in open arm (increased number of entries and time spent) is said to be anxiolytic. Control sampleof batch B exhibited anti-anxiety activity comparable to diazepam, and batches $\mathrm{A}$ and $\mathrm{C}$ showed statistically lower activity than diazepam (Table 3 ). However, this activity of the stability

Table 3: Effect of different treatments on behavior of mice in elevated plus maze model.

\begin{tabular}{lllll}
\hline Treatment & $\begin{array}{l}\text { Entries in } \\
\text { open arm }\end{array}$ & $\begin{array}{l}\text { Time spent } \\
\text { in open arm } \\
\text { (seconds) }\end{array}$ & $\begin{array}{l}\text { Entries in } \\
\text { closed arm }\end{array}$ & $\begin{array}{l}\text { Time spent } \\
\text { in closed arm } \\
\text { (seconds) }\end{array}$ \\
\hline $\begin{array}{l}\text { Vehicle } \\
\text { control }\end{array}$ & $2.00 \pm 0.36$ & $59.33 \pm 8.18$ & $8.50 \pm 0.43$ & $240.67 \pm 8.18$ \\
$\begin{array}{l}\text { Diazepam } \\
\text { Batch A }\end{array}$ & $6.50 \pm 0.43$ & $101.67 \pm 5.59$ & $5.00 \pm 0.36$ & $198.33 \pm 5.59$ \\
0 month & $5.00 \pm 0.58^{\mathrm{b}}$ & $80.33 \pm 10.32$ & $4.67 \pm 0.33^{\mathrm{b}}$ & $219.67 \pm 10.32$ \\
3 month & $4.83 \pm 0.31^{\mathrm{b}}$ & $72.33 \pm 8.29$ & $4.67 \pm 0.42^{\mathrm{b}}$ & $227.67 \pm 8.29$ \\
6 month & $4.50 \pm 0.22^{\mathrm{b}}$ & $68.67 \pm 5.44^{\mathrm{c}}$ & $5.00 \pm 0.52^{\mathrm{b}}$ & $231.33 \pm 5.44^{\mathrm{c}}$ \\
9 month & $4.33 \pm 0.62^{\mathrm{b}, \mathrm{c}}$ & $68.50 \pm 7.31^{\mathrm{c}}$ & $5.17 \pm 0.65^{\mathrm{b}}$ & $231.50 \pm 7.31^{\mathrm{c}}$ \\
12 month & $4.00 \pm 0.36^{\mathrm{b}, \mathrm{c}}$ & $70.00 \pm 6.59^{\mathrm{c}}$ & $5.67 \pm 0.49^{\mathrm{b}}$ & $230.00 \pm 6.59^{\mathrm{c}}$ \\
Batch B & & & & \\
0 month & $7.17 \pm 0.70^{\mathrm{b}}$ & $105.67 \pm 8.91^{\mathrm{b}}$ & $5.17 \pm 0.79^{\mathrm{b}}$ & $194.33 \pm 8.91^{\mathrm{b}}$ \\
3 month & $6.50 \pm 0.76^{\mathrm{b}}$ & $102.33 \pm 10.63^{\mathrm{b}}$ & $6.67 \pm 0.49$ & $197.67 \pm 10.63^{\mathrm{b}}$ \\
6 month & $6.17 \pm 0.48^{\mathrm{b}}$ & $101.67 \pm 7.70^{\mathrm{c}}$ & $6.83 \pm 0.48$ & $198.33 \pm 7.70^{\mathrm{b}}$ \\
9 month & $6.00 \pm 0.73^{\mathrm{b}}$ & $100.83 \pm 5.55^{\mathrm{b}}$ & $7.17 \pm 0.87$ & $199.17 \pm 5.55^{\mathrm{b}}$ \\
12 month & $6.00 \pm 0.45^{\mathrm{b}}$ & $98.00 \pm 6.31^{\mathrm{b}}$ & $7.67 \pm 0.72^{\mathrm{c}}$ & $202.00 \pm 6.31^{\mathrm{b}}$ \\
Batch C & & & & \\
0 month & $4.83 \pm 0.60^{\mathrm{b}}$ & $98.17 \pm 8.00^{\mathrm{b}}$ & $4.33 \pm 0.42^{\mathrm{b}}$ & $201.83 \pm 8.00^{\mathrm{b}}$ \\
3 month & $4.00 \pm 0.26^{\mathrm{c}}$ & $71.17 \pm 4.88^{\mathrm{c}}$ & $4.83 \pm 0.31^{\mathrm{b}}$ & $228.83 \pm 4.88^{\mathrm{c}}$ \\
6 month & $3.83 \pm 0.31^{\mathrm{c}}$ & $68.33 \pm 5.50^{\mathrm{c}}$ & $5.17 \pm 0.40^{\mathrm{b}}$ & $231.67 \pm 5.50^{\mathrm{c}}$ \\
9 month & $3.74 \pm 0.28$ & $66.93 \pm 6.24$ & $5.56 \pm 0.68$ & $233.84 \pm 6.12$ \\
12 month & $3.61 \pm 0.54$ & $63.85 \pm 5.72$ & $5.93 \pm 0.57$ & $235.08 \pm 7.63$ \\
\hline
\end{tabular}

Values are expressed as mean \pm SEM, $(n=6)$. Statistical analysis was done by one way ANOVA followed by Dunnet's multiple comparison test; bp $<0.05$ compared with vehicle control group; $\mathrm{cp}<0.05$ compared with diazepam treated group 
samples withdrawn at 3, 6, 9 and 12 monthsof the study was decreased, though insignificantly, gradually with time (Table 3 ). It suggested that antianxiety activity was maximumin control sample, and it decreased insignificantly with time upto 12 months.

In LDTT, tendency of an animal to stay in light and dark space is studied. Animal having the propensity to enter the light space and stay there are said to be less anxious. In this test, control sample of batch B exhibited anti-anxiety activity comparable to diazepam whereas those of batches $\mathrm{A}$ and $\mathrm{C}$ showed the activity lower than diazepam (Table 4). Stability samples withdrawn at 3, 6, 9 and 12 months showed a gradual decrease in permanence in the light space which suggested that antianxiety activity was maximum in control sample and

Table 4: Effect of different treatments on behavior of mice in light-dark transition model.

\begin{tabular}{|c|c|c|c|c|}
\hline Treatment & $\begin{array}{l}\text { Entries in } \\
\text { light space }\end{array}$ & $\begin{array}{l}\text { Time spent in light } \\
\text { space (seconds) }\end{array}$ & $\begin{array}{l}\text { Entries in } \\
\text { dark space }\end{array}$ & $\begin{array}{l}\text { Time spent in dark } \\
\text { space (seconds) }\end{array}$ \\
\hline Control & $3.00 \pm 0.36$ & $87.67 \pm 5.70$ & $7.17 \pm 0.31$ & $212.33 \pm 5.70$ \\
\hline Diazepam & $5.50 \pm 0.43$ & $138.17 \pm 9.77$ & $3.00 \pm 0.26$ & $161.83 \pm 9.77$ \\
\hline \multicolumn{5}{|l|}{ Batch A } \\
\hline 0 month & $4.83 \pm 0.48^{\mathrm{b}}$ & $119.50 \pm 7.80$ & $3.17 \pm 0.31^{\mathrm{b}}$ & $180.50 \pm 7.80$ \\
\hline 3 month & $4.83 \pm 0.60^{\mathrm{b}}$ & $106.50 \pm 9.50$ & $4.50 \pm 0.56^{\mathrm{b}}$ & $193.50 \pm 9.50$ \\
\hline 6 month & $4.67 \pm 0.67$ & $102.17 \pm 4.64^{\mathrm{c}}$ & $4.67 \pm 0.49^{\mathrm{b}}$ & $197.83 \pm 4.64^{\mathrm{c}}$ \\
\hline 9 month & $4.00 \pm 0.36$ & $101.50 \pm 9.40^{c}$ & $4.67 \pm 0.33^{b}$ & $198.50 \pm 9.40^{c}$ \\
\hline 12 month & $3.67 \pm 0.42^{c}$ & $103.00 \pm 5.24^{\mathrm{c}}$ & $5.33 \pm 0.49^{\mathrm{b}, \mathrm{c}}$ & $197.00 \pm 5.24^{\mathrm{c}}$ \\
\hline \multicolumn{5}{|l|}{ Batch B } \\
\hline 0 month & $5.83 \pm 0.40^{\mathrm{b}}$ & $135.67 \pm 10.90^{\mathrm{b}}$ & $4.17 \pm 0.48^{b}$ & $164.33 \pm 10.90^{\mathrm{b}}$ \\
\hline 3 month & $5.50 \pm 0.43^{\mathrm{b}}$ & $131.17 \pm 9.06^{\mathrm{b}}$ & $5.33 \pm 0.21^{\mathrm{b}, \mathrm{c}}$ & $168.83 \pm 9.06^{\mathrm{b}}$ \\
\hline 6 month & $5.33 \pm 0.33^{\mathrm{b}}$ & $127.17 \pm 9.58^{\mathrm{b}}$ & $5.33 \pm 0.72^{\mathrm{b}, \mathrm{c}}$ & $172.83 \pm 9.58^{\mathrm{b}}$ \\
\hline 9 month & $4.83 \pm 0.31^{\mathrm{b}}$ & $124.67 \pm 8.91^{\mathrm{b}}$ & $6.33 \pm 0.49^{c}$ & $175.33 \pm 8.91^{\mathrm{b}}$ \\
\hline 12 month & $4.50 \pm 0.43$ & $127.83 \pm 8.61^{\mathrm{b}}$ & $6.33 \pm 0.49^{c}$ & $172.17 \pm 8.61^{\mathrm{b}}$ \\
\hline \multicolumn{5}{|l|}{ Batch C } \\
\hline 0 month & $4.83 \pm 0.40^{\mathrm{b}}$ & $109.67 \pm 6.46$ & $5.00 \pm 0.45^{\mathrm{b}, \mathrm{c}}$ & $190.33 \pm 6.46$ \\
\hline 3 month & $4.67 \pm 0.42$ & $103.50 \pm 7.06^{\mathrm{c}}$ & $5.17 \pm 0.48^{\mathrm{b}, \mathrm{c}}$ & $196.50 \pm 7.06^{\mathrm{c}}$ \\
\hline 6 month & $4.50 \pm 0.43$ & $101.33 \pm 6.91^{\mathrm{c}}$ & $5.50 \pm 0.22^{c}$ & $198.67 \pm 6.91^{\mathrm{c}}$ \\
\hline 9 month & $4.33 \pm 0.28$ & $99.76 \pm 5.89$ & $6.02 \pm 0.45$ & $200.56 \pm 1.22$ \\
\hline 12 month & $4.07 \pm 0.45$ & $97.66 \pm 4.65$ & $7.12 \pm 0.34$ & $202.15 \pm 2.56$ \\
\hline
\end{tabular}

*Values are expressed as mean $\pm \mathrm{SEM},(\mathrm{n}=6)$. Statistical analysis was done by one way ANOVA followed by Dunnet's multiple comparison test; bp $<0.05$ compared with vehicle control group; $\mathrm{cp}<0.05$ compared with diazepam treated group
WHO Guided Real Time Stability Testing on Shankhpushpi Syrup 
Jain, A

Kaur, $\mathrm{J}$

Nancy,

Bansal, Y

Saini, B

Bansal, G it decreased, though insignificantly, with time up to 12 months. These results were in concordance with the results of EPM.

Open field test is used to evaluate the animal's emotional state. It examines anxiety related behavior characterized by normal aversion of the animal to an open area. Thus, animals removed from their acclimatized cage and placed in open environment express anxiety and fear, by showing alteration in behavioral parameters. The antianxiety activity is directly related to the number of entries and time spent in the central square but inversely related to the number of rearing and number of lines crossed during 5 minute stay of the animal in the open field (Brown, R.E. et al, 1999). Control sample of batch B exhibited antianxiety activity comparable to diazepam whereas batches $\mathrm{A}$ and $\mathrm{C}$ showed the activity lower than diazepam (Table 5). Stability samples showed a gradual decrease in permanence in the centre square, and increase in number of rearing and number of lines crossed of the model, which suggested that antianxiety activity was maximum in control sample and it decreased, though insignificantly, with time up to 12 months (Table 5).

These results of antianxiety activity evaluations in all three models indicated that control sample of batch B showed antianxiety activity equivalent to diazepam, and the activity of stability samples decreased gradually with storage time. The 12 month stability samples of each batch showed the activity lower than vehicle control. It suggested that the products may not be efficacious in alleviating anxiety after a shelf life of 12 months. A comparative analysis of all findings reveals that:

1. There is a good correspondence between percent decrease in antioxidant activity and in TPC in each batch after 12 months of shelf life with respect to control sample, which suggest that the anti-radical activity may be attributed to phenolic constituents in the product.

2. The extent of decrease in AChE inhibitory activity corresponds to the extent of decrease in antioxidant activity in each batch, which suggests that AChE inhibitory activity of the product may be attributed to antioxidant constituents.

3. Batch B exhibited maximum antianxiety activity whereas the best antioxidant and $\mathrm{AChE}$ inhibitory activities are exhibited by batch A. It suggests that components responsible for antianxiety activity may be different from those responsible for other activities.

4. Content of scopoletin is insignificantly different in batches A and B, and almost two times in batch C. These levels are found to correspond to none of the activities evaluated for three batches, which suggests that scopoletin may not be responsible for any of the activities tested. Also, it may not be a suitable marker for monitoring stability of the products. 
Table 5: Effect of different treatments on behavior of mice in open-field model.

\begin{tabular}{|c|c|c|c|c|}
\hline Treatment & $\begin{array}{l}\text { Number of } \\
\text { squares crossed }\end{array}$ & Rearing & $\begin{array}{l}\text { Centre squares } \\
\text { entries }\end{array}$ & $\begin{array}{l}\text { Duration in centre } \\
\text { squares (seconds) }\end{array}$ \\
\hline Control & $93.50 \pm 2.98$ & $34.17 \pm 1.89$ & $1.50 \pm 0.22$ & $2.33 \pm 0.21$ \\
\hline Diazepam & $37.67 \pm 2.28$ & $16.17 \pm 0.98$ & $5.50 \pm 0.34$ & $12.00 \pm 0.89$ \\
\hline \multicolumn{5}{|l|}{ Batch A } \\
\hline 0 month & $49.50 \pm 3.77^{b}$ & $13.50 \pm 1.71^{\mathrm{b}}$ & $2.33 \pm 0.33^{\mathrm{c}}$ & $4.67 \pm 0.99^{c}$ \\
\hline 3 month & $50.00 \pm 1.21^{\mathrm{b}}$ & $13.17 \pm 1.08^{\mathrm{b}}$ & $2.17 \pm 0.31^{\mathrm{c}}$ & $3.67 \pm 0.56^{c}$ \\
\hline 6 month & $50.33 \pm 4.07^{\mathrm{b}}$ & $14.33 \pm 2.49^{\mathrm{b}}$ & $2.33 \pm 0.21^{\mathrm{c}}$ & $3.33 \pm 0.42^{\mathrm{c}}$ \\
\hline 9 month & $56.50 \pm 4.14^{\mathrm{b}, \mathrm{c}}$ & $14.50 \pm 1.75^{b}$ & $2.33 \pm 0.33^{\mathrm{c}}$ & $3.17 \pm 0.31^{\mathrm{c}}$ \\
\hline 12 month & $60.17 \pm 3.88^{\mathrm{b}, \mathrm{c}}$ & $14.67 \pm 2.52^{b}$ & $1.83 \pm 0.31^{\mathrm{c}}$ & $2.83 \pm 0.31^{\mathrm{c}}$ \\
\hline \multicolumn{5}{|l|}{ Batch B } \\
\hline 0 month & $69.00 \pm 2.53^{\mathrm{b}, \mathrm{c}}$ & $15.17 \pm 0.83^{b}$ & $5.00 \pm 0.58^{b}$ & $11.83 \pm 2.34^{\mathrm{b}}$ \\
\hline 3 month & $71.83 \pm 3.38^{\mathrm{b}, \mathrm{c}}$ & $16.50 \pm 2.38^{b}$ & $5.00 \pm 0.45^{\mathrm{b}}$ & $9.50 \pm 2.22^{\mathrm{b}}$ \\
\hline 6 month & $75.50 \pm 9.34^{\mathrm{c}}$ & $22.33 \pm 2.43^{b}$ & $4.50 \pm 0.43^{b}$ & $8.83 \pm 2.06^{\mathrm{b}}$ \\
\hline 9 month & $78.67 \pm 5.35^{\mathrm{c}}$ & $22.67 \pm 1.67^{\mathrm{b}}$ & $4.50 \pm 0.43^{b}$ & $6.17 \pm 1.08^{c}$ \\
\hline 12 month & $80.67 \pm 7.35^{\mathrm{c}}$ & $23.00 \pm 2.39^{\mathrm{b}}$ & $3.67 \pm 0.42^{\mathrm{b}, \mathrm{c}}$ & $4.67 \pm 0.76^{c}$ \\
\hline \multicolumn{5}{|l|}{ Batch C } \\
\hline 0 month & $41.17 \pm 4.76^{b}$ & $17.33 \pm 2.16^{\mathrm{b}}$ & $4.83 \pm 0.95^{\mathrm{b}}$ & $8.83 \pm 0.95^{\mathrm{b}}$ \\
\hline 3 month & $44.00 \pm 3.64^{\mathrm{b}}$ & $18.67 \pm 1.93^{\mathrm{b}}$ & $4.50 \pm 0.34^{\mathrm{b}}$ & $8.67 \pm 0.88^{\mathrm{b}}$ \\
\hline 6 month & $54.83 \pm 2.57^{\mathrm{b}}$ & $21.00 \pm 2.07^{\mathrm{b}}$ & $4.00 \pm 0.36^{\mathrm{b}}$ & $8.50 \pm 0.88^{\mathrm{b}}$ \\
\hline 9 month & $56.92 \pm 3.55$ & $23.13 \pm 1.87$ & $3.62 \pm 0.28$ & $7.91 \pm 0.67$ \\
\hline 12 month & $57.88 \pm 2.33$ & $24.11 \pm 1.04$ & $3.50 \pm 0.47$ & $7.62 \pm 0.45$ \\
\hline
\end{tabular}

*Values are expressed as mean \pm SEM, $(n=6)$. Statistical analysis was done by one way ANOVA followed by Dunnet's multiple comparison test; a $\mathrm{p}<0.05$ compared with vehicle control group; $\mathrm{b} \mathrm{p}<0.05$ compared with diazepam treated group

\section{CONCLUSION}

Stability testing was conducted on three batches of commercially available herbal formulations containing $C$. pluricaulis and B. monnieriunder the ICH recommended condition for long term stability $\left(\left(30 \pm 2^{\circ} \mathrm{C} / 65 \pm 5 \% \mathrm{RH}\right)\right.$. The samples were withdrawn at 3, 6, 9 and 12 months and were evaluated for physical and chemical stability and for various biological activities using in vitro and in vivo models. No change in the physical parameters such as clarity, color, odor, taste, viscosity and $\mathrm{pH}$ was found in any of the stability samples w.r.t. the control. The total phenolic content decreased with time in all the three batches w.r.t. the respective control. The content of scopoletin also decreased with time in all the batches w.r.t. the respective control as depicted by HPLC-UV data. It was found that more than $50 \%$ of scopoletin degraded in each batch just after 6 months upon storage which indicated that
WHO Guided Real Time Stability Testing on Shankhpushpi Syrup 
Jain, A

Kaur, $\mathrm{J}$

Nancy,

Bansal, Y

Saini, B

Bansal, G

scopoletin is not very stable at long term study conditions. Comparison of LC-UV fingerprints of the three batches revealed that batch $\mathrm{A}$ and $\mathrm{C}$ have similar compositions but batch B is significantly different from the other two. Antioxidant activity of the three batches was found to decrease insignificantly and gradually up to 12 months. Acetyl cholinesterase (ACHE) inhibitory activity was also found to decrease in each batch, though insignificantly, with time. Antianxiety activity was evaluated through animal studies using three different models i.e., Elevated-Plus maze model, Light-Dark transition model and Open-field model. The results of all three models revealed that antianxiety activity was maximum in control (0 month) sample and decreased, though insignificantly, with time up to 12 months. Further, a comparison of all the pharmacological activities and other parameters of stability testing in different batches of the product revealed significant batch to batch variations. Thus, in the present study, changes in marker content and biological activities of the product during storage at long term stability conditions suggest that the shelf life provided on the label claim of the product do not represent its actual shelf life. Further studies should be conducted to establish the proper storage conditions and shelf life of the product.

\section{CONFLICTS OF INTEREST}

The authors declare that there are no conflicts of interest regarding the publication of this paper.

\section{ACKNOWLEDGEMENT}

The authors are thankful to DBT-Punjabi University Patiala Interdisciplinary Programme in Life Sciences for Advance Research andEducation for providing the partial financial assistance in carrying out the study (File No.: BT/PR4548/ $\mathrm{INF} / 22 / 146 / 2012)$.

\section{REFERENCES}

[1] Arslan, E., Yener, M.E. and Esin, A. (2005)'Rheological characterization of tahin/pekmez (sesame paste/concentrated grape juice) blends'.Journal of Food Engineering, Vol 69, 2, pp. 167-172. https://doi.org/10.1016/j.jfoodeng.2004.08.010

[2] Bourin, M. and Hascoet, M. (2003) 'The mouse light/dark box test'.European Journalof Pharmacology, Vol 463, 1-3, pp. 55-65. https://doi.org/10.1016/s0014-2999(03)01274-3

[3] Brown, R.E., Corey, S.C. and Moore, A.K. (1999) 'Differences in Measures of Exploration and Fear in MHC-Congenic C57BL/6J and B6-H-2K Mice'.Behavior genetics, Vol 29, 4, pp. 263-271. https://doi.org/10.1023/A:1021694307672

[4] Committee for Proprietary Medicinal Products (2003) Guideline on stability testing: Stability testing of existing active substances and related finished products CPMP/QWP/122/02 Rev1 corr., European Medicines Agency, London, UK. 
[5] Committee for Proprietary Medicinal Products (2003)Stability testing of New Drug Substances and Products CPMP/ICH/2736/99, European Medicines Agency, London, UK.

[6] Committee on Herbal Medicinal Products (2008)Markers used for Quantitative and Qualitative analysis of Herbal Medicinal Products and Traditional Herbal Medicinal Products EMEA/ HMPC/253629/07, European Medicines Agency, London, UK.

[7] Committee on Herbal Medicinal Products (2008)Quality of Combination Herbal Medicinal Products/Traditional Herbal Medicinal Products EMEA/HPMC/CHMP/CVMP/214869, European Medicines Agency, London, UK.

[8] Committee on Herbal Medicinal Products (2010)Reflection paper on stability testing of Herbal Medicinal Products and Traditional Herbal Medicinal Products EMEA/HMPC/3626/09, European Medicines Agency, London, UK.

[9] Ellman, G.L., Courtney, K.D., Andres, V. and Featherstone, R.M. (1961)'A new and rapid colorimetric determination of acetylcholinesterase activity'.Biochemical Pharmacology, Vol 7, 2, pp. 88-95. https://doi.org/10.1016/0006-2952(61)90145-9

[10] Fu, L., Xu, B.T., Gan, R.Y., Zhang, Y., Xu, X.R., et al. (2011)'Total phenolic contents and antioxidant capacities of herbal and tea infusions'. International Journal of Molecular Sciences, Vol 12, 4, pp. 2112-2124. https://doi.org/10.3390/ijms 12042112

[11] International Conference on Harmonization (2003) Stability testing of New Drug Substances and Products ICH Q1A(R2), International Conference on Harmonization, Geneva, Switzerland.

[12] Kulkarni, S.K. (1999),'Handbook of Experimental Pharmacology' (3rd Ed.), Delhi.Vallabh Prakashan.

[13] Kumari, S., Shukla, G. and Rao A.S. (2011) 'The Present Status of Medicinal Plants-Aspects and Prospects'. International Journal of Research in Pharmaceutical and Biomedical Sciences, Vol 2, 1, pp. 19-22.

[14] Locatelli, M., Gindro, R., Travaglia, F., Coïsson, J.D., Rinaldi, M., et al. (2009)'Study of the DPPH scavenging activity: Development of a free software for the correct interpretation of data'. Food Chemistry, Vol 114, 3, pp. 889-897. https://doi.org/10.1016/j.foodchem.2008.10.035

[15] Phrompittayarat, W., Wittaya-areekul, S., Jetiyanon, K., Putalun, W., Tanaka, H., et al. (2008)'Stability studies of saponins in Bacopamonnieri dried ethanolic extracts'. Planta Medica, Vol 74, 14, pp. 1756-1763. https://doi.org/10.1055/s-0028-1088311

[16] Reagan-Shaw, S., Nihal, M. and Ahmad, N. (2008)'Dose translation from animal to human studies revisited'. The FASEB Journal, Vol 22, 3, pp. 659-661.

https://doi.org/10.1096/fj.07-9574LSF

[17] Shahare, M.D. and D'Mello, P.M. (2010)'Standardization of BacopaMonnieri and its Formulations with reference to Bacoside A, by High Performance Thin Layer Chromatography'. International Journal of Pharmacognosy and Phytochemical Research, Vol 2, 4, pp. 8-12.

[18] Srivastava, P., Raut, H.N., Puntambekar, H.M., Upadhye, A.S. and Desai, A.C. (2010)'Stability studies of crude plant material of Bacopamonnieri and its effect on free radical scavenging activity'.Journal of Phytology, Vol 2, 8, pp. 103-109.

[19] Srivastava, P., Raut, H.N., Puntambekar, H.M. and Desai, A.C. (2012)'Stability studies of crude plant material of Bacopamonnieri and quantitative determination of bacopasideI and bacoside A by HPLC'. PhytochemicalAnalysis, Vol 23, 5, pp. 502-507. https://doi.org/10.1002/pca.2347

[20] World Health Organisation (2009)Stability testing of active pharmaceutical ingredients and finished pharmaceutical products WHO Technical Report Series, No. 953, World Health Organisation, Geneva.
WHO Guided

Real Time

Stability Testing

on Shankhpushpi

Syrup 